\title{
D-Ribose Competitively Reverses Inhibition by D-Psicose of Larval Growth in Caenorhabditis elegans
}

\author{
Masashi Sato, Nobutoshi Yokor, Hiroyuki Kurose, and Toru Yamasaki* \\ Department of Applied Biological Science, Kagawa University; Miki-Ikenobe, Kagawa 761-0795, Japan. \\ Received January 13, 2009; accepted February 4, 2009; published online February 9, 2009
}

\begin{abstract}
D-Psicose inhibits the growth of L1 stage Caenorhabditis elegans. Sugars, involved in the pentose phosphate pathway, were examined for their ability to reverse the inhibition. Among these sugars, D-ribose specifically exerted reversing activity in a competitive manner. The ingested sugars are probably phosphorylated, although it remains to be seen whether D-psicose is phosphorylated. The structural similarity of D-psicofuranose 6-phosphate (Pf6P) or D-psicofuranose (Pf) to D-ribofuranose 5-phosphate (Rf5P) suggests that Pf6P or Pf is reversibly docked in the active site(s) of ribose-5-phosphate isomerase(s) to act as an antimetabolite to Rf5P, leading to inhibition of the biosynthesis of nucleic acids. D-Psicose was much less potent against the L4 stage than against the L1 stage. This is probably because in the L4 stage the somatic cell lineages come to an end and the number of germ-line nuclei increases to about 1000.
\end{abstract}

Key words D-ribose; D-psicose; antimetabolite; Caenorhabditis elegans; growth

Certain ketohexose stereoisomers have been shown to exert biological activity. L-Sorbose induces glycolytic limitation in canine erythrocytes, leading to hemolysis. ${ }^{1)}$ Phosphorylation of $\mathrm{D}$-(fuctose ${ }^{2)}$ or D-tagatose ${ }^{3)}$ in the liver causes severe metabolic disturbances, due to the accumulation of phosphorylated intermediates. It was recently shown that, among D- and L-forms of ketohexose stereoisomers (psicose, sorbose, fructose, and tagatose), as well as D-glucose and Dgalactose, the rare sugar D-psicose specifically inhibited the motility, growth, and reproductive maturity of L1 stage Caenorhabditis elegans. ${ }^{4)}$

D-Psicose was recorded as a constituent moiety of the antibiotic psicofuranine, ${ }^{5)}$ having marked antibacterial ${ }^{6)}$ and antitumor $^{7)}$ activities in vivo, from culture filtrates of Streptomyces hygroscopicus var. decoyicus. ${ }^{8)}$ The furanose form of D-psicose resembles in structure that of D-ribose (Fig. 1). This structural resemblance suggests an antimetabolite mode of action. The purpose of this paper is to identify the biochemical target of D-psicose in larvae of C. elegans by testing compounds for their ability to reverse the inhibitory activity of D-psicose and to propose a possible inhibiton mechanism of D-psicose.
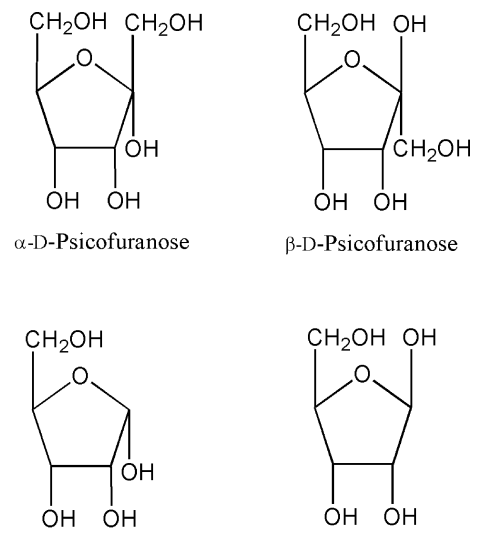

$\alpha$-D-Ribofuranose

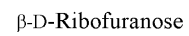

Fig. 1. Structures of D-Psicose and D-Ribose in the Cyclic Furanose Form

\section{MATERIALS AND METHODS}

Chemicals D-Ribose and sodium D-gluconate were purchased from Wako, Osaka, Japan; D-ribulose, from Omicron, South Bend, IN, U.S.A.; and D-erythrose and D-sedoheptulose, Sigma-Aldrich, St. Louis, MO, U.S.A. A variety of chemicals needed to prepare $C$. elegans cultivation and handling media ${ }^{9)}$ were obtained from Wako. All chemicals used here were of analytical grade.

L1 and L4 Larvae of C. elegans Standard conditions were used for $C$. elegans cultivation. ${ }^{9)}$ A stock culture of the Bristol strain of $C$. elegans was incubated at $20^{\circ} \mathrm{C}$ in a liquid growth medium (LGM), i.e., complete $\mathrm{S}$ medium supplemented with Escherichia coli strain OP50 (28.6 g wet weight per liter), by shaking for $7 \mathrm{~d}$. Dauer stage larvae, induced by starving the culture for $14 \mathrm{~d}$, were transferred onto $3.5-\mathrm{cm}$ NGM agar plates with E. coli at $20^{\circ} \mathrm{C}$ and L4 larvae were prepared after $24 \mathrm{~h}^{10)}$ Eggs were collected by treating eggbearing adults with $5.4 \%$ alkaline hypochlorite, followed by shaking the eggs in M9 buffer at $20^{\circ} \mathrm{C}$ for $22 \mathrm{~h}$ to prepare L1 larvae.

Experiments Individual three-L1 larva sets were incubated in each of $250-\mu 1$ hemiellipsoidal wells holding $200 \mu \mathrm{l}$ of LGM containing D-psicose $(111 \mathrm{~mm})$ with and without one of the compounds to be tested for reversing activity at $20^{\circ} \mathrm{C}$ for $84 \mathrm{~h}$, in accordance with the previous method. ${ }^{4)} \mathrm{L} 1$ larvae were incubated as controls in LGM. Similarly, three-L4 or -L1 larva sets were incubated in LGM $(200 \mu \mathrm{l})$ with and without D-psicose $(167 \mathrm{~mm})$ at $20^{\circ} \mathrm{C}$. Eighteen larvae were used at each concentration.

Motility, Growth, and Reproductive Parameters Nematode motility is expressed as a motility index, $\sum n N_{n}$ / $\sum N_{n}^{4,11)} ; N_{n}$ is the number of worms showing the movements stated in $n=3$ (fully sinusoidal locomotion movements), $n=2$ (slow movements), $n=1$ (feeble wriggling of the upper or lower part), or $n=0$ (motionlessness, death). The worms in the incubation wells were kept at $4{ }^{\circ} \mathrm{C}$ for $0.5 \mathrm{~h}$ to depress their movements, and pictures were taken with a CCD camera attached to a microscope (Olympus BX51). Body lengths were measured by the previous method, ${ }^{4)}$ which is virtually 


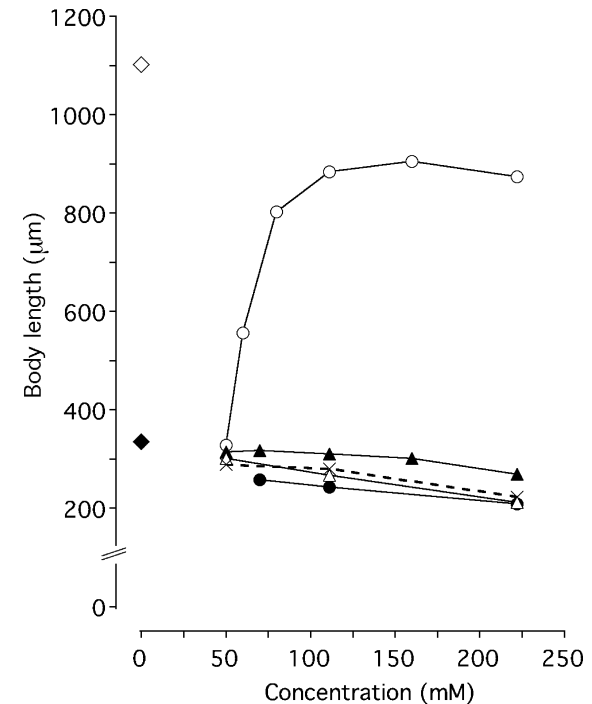

Fig. 2. Larval Growth in LGM Containing Both D-Psicose at $111 \mathrm{~mm}$ and One of the Other Sugars at Concentrations Indicated in the Figure

O, D-ribose; $\boldsymbol{\Delta}$, D-ribulose; $\triangle$, D-erythrose; $\times$, D-sedoheptulose; $\bullet$, sodium D-gluconate; $\diamond$, larval growth in LGM containing only D-psicose $(111 \mathrm{~mm})$; and $\diamond$, that in LGM.

identical to that described by Fujiwara et al. ${ }^{12)}$; the software was Mac SCOPE version 2.5 (Mitani, Tokyo, Japan). The egg-bearing rate is given as a percentage of worms bearing eggs in the uterus.

\section{RESULTS}

Several sugars, involved in the pentose phosphate pathway, were examined for reversal of inhibition by D-psicose (111 mM) of larval growth during a period of $84 \mathrm{~h}$ (Fig. 2). DRibulose, sodium D-gluconate, D-erythrose, and D-sedoheptulose were all ineffective in reversing the inhibition by D-psicose. In contrast, D-ribose did reverse activity ( $\bigcirc$ in Fig. 2). At $160 \mathrm{~mm}$, mean body length \pm S.D. of worms $(N=18)$ reached $905 \pm 124 \mu \mathrm{m}$ after $84 \mathrm{~h}$; i.e., the mean value was 2.7 times that ( in Fig. 2) of worms incubated in LGM containing only D-psicose (111 mM), or $82 \%$ that $(\diamond$ in Fig. 2$)$ of controls in LGM. In addition, after $84 \mathrm{~h}$ the initial motility index of 3 decreased to $2.9 \pm 0.2$ only, and $61 \pm 25 \%$ of L1 larvae became egg-bearing adults. For each D-ribose concentration, the D-psicose concentration against body length was plotted into a straight line, which was approximately parallel with the line given by worms in LGM containing only D-psicose (Fig. 3). The results show that D-psicose's inhibition of larval growth decreased when the concentration of D-ribose added to LGM increased. The body length for a ratio of D-ribose to D-psicose $(1: 1)$ was almost constant, $860-884 \mu \mathrm{m}$ (Table 1).

Furthermore, D-psicose (167 mM) was examined for its potency against the reproductive maturity of L4 larvae in LGM. During a period of $30 \mathrm{~h}$, this sugar caused a slight reduction of egg-bearing rates only, and so all L4 larvae became eggbearing adults within $36 \mathrm{~h}$, compared with $30 \mathrm{~h}$ for controls (Fig. 4).

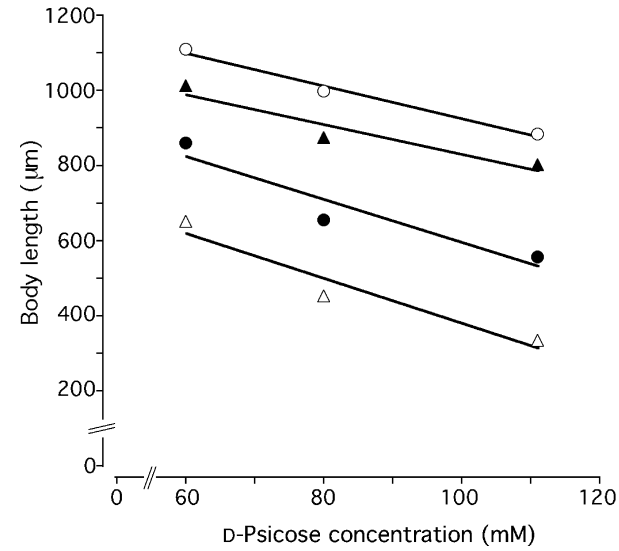

Fig. 3. Larval Growth in LGM Containing Both D-Psicose at Concentrations Indicated in the Figure and D-Ribose at $0 \mathrm{~mm}(\triangle), 60 \mathrm{~mm}(\bigcirc), 80 \mathrm{~mm}$ $(\mathbf{A})$, and $111 \mathrm{~mm}(\bigcirc)$

Table 1. Larval Growth in LGM Containing D-Psicose and D-Ribose at a Ratio of $1: 1$

\begin{tabular}{cccc}
\hline \hline $\begin{array}{c}\text { D-Psicose } \\
(\mathrm{mm})\end{array}$ & $\begin{array}{c}\text { D-Ribose } \\
(\mathrm{mm})\end{array}$ & Ratio & $\begin{array}{c}\text { Body length } \pm \text { S.D. } \\
(\mu \mathrm{m})\end{array}$ \\
\hline 111 & 111 & $1: 1$ & $884 \pm 151$ \\
80 & 80 & $1: 1$ & $875 \pm 136$ \\
60 & 60 & $1: 1$ & $860 \pm 107$ \\
\hline
\end{tabular}

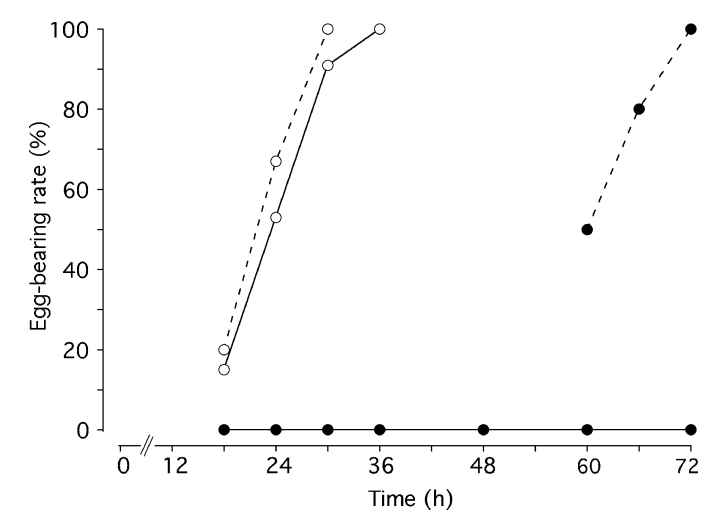

Fig. 4. Reproductive Maturity of L1 ( ) and L4 (O) Larvae in LGM with $(-)$ and without (---) D-Psicose at167 mm

\section{DISCUSSION}

Among the several sugars tested here, D-ribose specifically reversed inhibition by D-psicose of larval growth (Fig. 2). The results, including the observations on nematode motility and egg-bearing rate, suggest that the external supply of D-ribose to larvae in LGM containing D-psicose considerably compensated for a deficiency in D-ribose. Therefore, D-psicose appears to interfere with the bioconversion of D-ribulose to D-ribose in the larvae. With competitive inhibition the reaction rate for a certain ratio of metabolite to antimetabolite is almost constant regardless of their absolute values. ${ }^{13,14}$ This condition was fulfilled by D-ribose (Fig. 3, Table 1).

Ribose-5-phosphate isomerases (Rpis), which catalyze the interconversion of D-ribose 5-phosphate (R5P) and D-ribulose 5-phosphate $(\mathrm{Ru} 5 \mathrm{P}),{ }^{15)}$ are classified into type A (occurring in all three kingdoms of life) or type B (occurring in some 
bacteria and protozoa). ${ }^{16)}$ The cyclic $\alpha$ - and $\beta$-furanose forms are much more abundant in aqueous solution than the open-chain form. ${ }^{17}$ ) Recently, it has been proposed that the cyclic form (especially, the $\beta$ form) of R5P is initially docked in the active site of RpiB from Mycobacterium tuberculosis, which is causative of tuberculosis, and transformed to the open-chain form, leading to the isomerization reaction to Ru5P via the high-energy intermediate 1,2-cis-enediolate. ${ }^{18)}$ A similar hypothesis has been proposed for phosphoglucose isomerase. ${ }^{19)} \mathrm{D}$-Ribose, tested here, is probably phosphorylated in the larvae, as well as other sugars. On the other hand, it remains to be seen whether D-psicose will be phosphorylated. Among the resulting phosphates, D-ribofuranose 5-phosphate (Rf5P) structurally resembles D-psicofuranose 6-phosphate (Pf6P) or D-psicofuranose (Pf). C. elegans possesses a gene called rpia-1, that encodes a putative Rpi (http://www.wormbase.org/db/gene/gene?name=WBGene00015101; class $=$ Gene). Therefore, it is possible that $\mathrm{Pf6P}$ or Pf is reversibly bound in the active site of the relevant larval enzyme(s), probably Rpi(s), to act as an enzymeinhibitor. Thus, the antimetabolite mode of action appeared to be a block against the biosynthesis of nucleic acids.

D-Psicose was much less potent against the reproductive maturity of L4 larvae than against that of L1 larvae (Fig. 4). This appeared to be attributable to the fact that in the L4 stage the somatic cell lineages come to an $\mathrm{end}^{20)}$ and the number of germ-line nuclei increases to about $1000 .{ }^{21)}$ Further investigations, including isolation of Rpi(s) from C. elegans, are needed to detail the inhibition mechanism of D-psicose.

Acknowledgements The authors are grateful to Guest Professor Ken Izumori of Kagawa University for supplying the sample of D-psicose.

\section{REFERENCES}

1) Goto I., Inaba M., Shimizu T., Maede Y., Am. J. Vet. Res., 55, $291-$ 294 (1994).

2) Masson S., Henriksen O., Stengaard A., Thomsen C., Quistorff B., Biochim. Biophys. Acta, 1199, 166-174 (1994).

3) Buemann B., Gesmar H., Astrup A., Quistorff B., Metabolism, 49, 1335-1339 (2000).

4) Sato M., Kurose H., Yamasaki T., Izumori K., J. Nat. Med., 62, 244 246 (2008).

5) Schroeder W., Hoeksema H., J. Am. Chem. Soc., 81, 1767-1768 (1959).

6) Lewis C., Reames H. R., Rhuland L. E., Antibiot. Chemother., 9, 421-426 (1959).

7) Evans J. S., Gray J. E., Antibiot. Chemother, 9, 675-683 (1959).

8) Eble T. E., Hoeksema H., Boyack G. A., Savage G. M., Antibiot. Chemother, 9, 419-420 (1959).

9) Lewis J. A., Fleming J. T., "Caenorhabditis elegans, Modern Biological Analysis of an Organism," ed. by Epstein H. F., Shakes D. C., Academic Press, New York, 1995, pp. 3-29.

10) Wadsworth W. G., Riddle D., Dev. Biol., 132, 167-173 (1989).

11) Kiuchi F., Miyashita N., Tsuda Y., Kondo K., Yoshimura H., Chem. Pharm. Bull., 35, 2880-2886 (1987).

12) Fujiwara M., Sengpta P., McIntire S. L., Neuron, 36, 1091-1102 (2002).

13) Hanka L. J., J. Bacteriol., 80, 30-36 (1960).

14) Fruton J. S., Simmonds S., "General Biochemistry," John Wiley \& Sons, New York, 1958, pp. 244-283.

15) Sorensen K. I., Hove-Jensen B., J. Bacteriol., 178, 1003-1011 (1996).

16) Zhang R.-G., Andersson C. E., Skarina T., Evdokimova E., Edwards A. M., Joachimiak A., Savchenko A., Mowbray S. L., J. Mol. Biol., 332, 1083-1094 (2003).

17) Pierce J., Serianni A. S., Barker R., J. Am. Chem. Soc., 107, 2448 2456 (1985).

18) Roos A. K., Burgos E., Ericsson D. J., Salmon L., Mowbray S. L., J. Biol. Chem., 280, 6416-6422 (2005).

19) Lee J. H., Chang K. Z., Patel V., Jeffery C. J., Biochemistry, 40, $7799-7805$ (2001).

20) Sulston J., "The Nematode Caenorhabditis elegans," ed. by Wood W. B., The Community of C. elegans Researchers, Cold Harbor Laboratory, New York, 1988, pp. 123-155.

21) Kimble J., Ward S., " The Nematode Caenorhabditis elegans," ed. by Wood W. B., The Community of C. elegans Researchers, Cold Harbor Laboratory, New York, 1988, pp. 191-213. 